\title{
Buckling Behavior of Cold-Formed Studs with Thermal Perforations
}

\author{
Marsel Garifullin ${ }^{1, *}$, Alexey Sinelnikov ${ }^{1}$, Maria Bronzova ${ }^{1}$, Boštjan Kovacic ${ }^{2}$, and Rok \\ Kamnik $^{2}$ \\ ${ }^{1}$ Peter the Great Saint-Petersburg Polytechnic University, Institute of Civil Engineering, 195251 \\ St.Petersburg, Russia \\ ${ }^{2}$ University of Maribor, Faculty of Civil Engineering, 2000 Maribor, Slovenia
}

\begin{abstract}
Studies have shown that the optimal structural scheme for lowrise buildings that meets all regulatory requirements is a frame system. In this connection, thin-walled cold-formed steel (CFS) profiles seem to be the best material for constructing light steel framed (LSF) walls. The framework of LSF walls is usually constructed from CFS C-shaped profiles. To increase the thermal effectiveness of a wall, CFS profiles usually have thermal perforations and thus are called thermoprofiles. However, these openings have a negative impact on bearing capacity of profiles and require accurate evaluation. In this article a relatively new reticular-stretched thermoprofile with diamond-shaped openings is considered. The article deals with the buckling analysis of perforated CFS $\mathrm{C}$-sections subjected to compression.
\end{abstract}

\section{Introduction}

Thin-walled cold-formed steel (CFS) sections are widely used in various fields of industrial and civil engineering, bridges, storage racks, car bodies, railway coaches, transmission towers and poles, various types of equipment [1-6].

Over the last decade CFS structures have been actively used in the construction of LSF systems in residential housing $[7,8]$. This caused a growing interest to the issue of their mechanical properties [9-11]. Rybakov [12, 13] presented four types of finite elements to analyze cold-formed members with various boundary conditions on the ends. Belyj [14] introduced a new method for the approximate estimation of CFS structures service life in buildings. Al Ali [15-17] investigated thin-walled cold-formed steel members with closed cross-sections. Tusnin [18-22] introduced thin-walled finite elements to analyze spatial cold-formed structures with open cross sections. Tusnina [23-25] presented a finite element analysis of cold-formed Z-purlins supported by sandwich panels. Nackenhorst [26] investigated the problem of initial geometric imperfections on buckling behavior of CFS Cshaped compressed columns. Prokic [27-29] analyzed the behavior of thin-walled open section I-beams under torsion and bending. Björk [30-32] studied the influence of residual stresses on the fatigue strength of CFS rectangular hollow sections. Ungermann [33, 34]

*Corresponding author:273marcel@gmail.com 
dealt with experimental and numerical investigations on plain channels subjected to coupled instabilities. Post-buckling behavior of cold-formed steel columns was observed by Schafer [35].

To increase the thermal effectiveness of exterior LSF walls in framed residential buildings CFS profiles are usually perforated on webs and thus are called thermoprofiles (Fig. 1). Traditionally, thermoprofiles with longitudinal perforations are mostly used in construction. In this article a new type of perforated thermoprofile is considered - reticularstretched thermoprofile (hereinafter RST-profile). The key features of this profile are completely different (diamond-shaped) geometry of perforations and the presence of the intermediate longitudinal stiffener.

Due to the fact that RST-profile has been designed recently, nowadays very little research has been devoted to the investigation of its mechanical properties. Sinelnikov [3638] and Nazmeeva [39, 40] investigated the buckling behavior of compressed cold-formed columns made of RST-profiles. Trubina [41-44] analyzed the problem of local and global buckling of RST-profiles in bending.
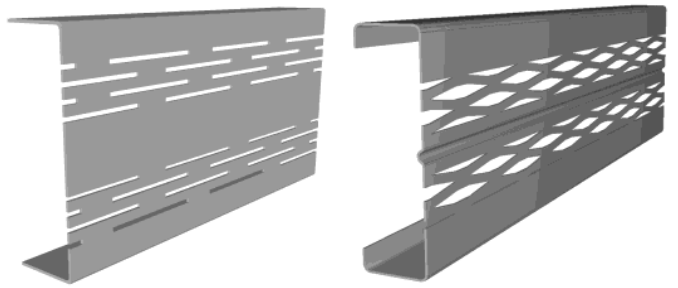

Fig. 1. Thermoprofiles: traditional (left) and reticular-stretched (right).

Despite the growing interest to RST-profiles, the influence of perforations on the resistance of profiles remains an open issue. Buckling behavior of these sections is also investigated very poorly.

This article deals with buckling performance of cold-formed C-sections made of RSTprofile. Firstly, the experimental results of the compressed columns are provided. The second part contains the nonlinear FE analysis of these columns.

\section{Experimental investigations}

Laboratory tests were carried out for the two types of specimens:

- RST-profiled columns without nodal connections at the ends, Sn (n -sample number);

- RST-profiled columns as part of the nodal connection, $\mathrm{Cn}$ ( $\mathrm{n}$ - sample number).

Experimental study of the profile was conducted in the laboratory of HAMK University, InnoSteel Sheet Metal Development Centre, Finland. The test specimens were produced by OOO Arsenal ST, Russia.

The steel used for the production of the profile had the following characteristics:

- Design strength: $350 \mathrm{~N} / \mathrm{mm}^{2}$;

- Zinc coating: $350 \mathrm{~g} / \mathrm{m}^{2}$;

- Zinc coating thickness: 25 microns.

The characteristics of the samples are shown in Table 1.

Table 1. Characteristics of the samples tested.

\begin{tabular}{|c|c|c|}
\hline Type & S1, S2, S3 & C1, C2, C3 \\
\hline Profile & TCc 200-45-2.0 & TCc 200-45-2.0 \\
\hline Length, mm & 1000 & 350 \\
\hline Boundary conditions & Top - pinned, bottom - pinned & Top - pinned, bottom - fixed \\
\hline
\end{tabular}


The ends of Sn specimens (Fig. 2a) were cut using a circular metal saw (not machined). Support wooden blocks (thickness $40 \mathrm{~mm}$; edge is positioned $3 \mathrm{~mm}$ from the end of the profile) were placed inside the ends of the columns. The lower ends of the specimen were placed on a hinged steel support. The load of a hydraulic cylinder was applied through a thick steel plate to the upper ends of the specimens. All the specimens were loaded using the displacement control until the failure. The loading rate was $3 \mathrm{~mm} / \mathrm{min}$.

Every Cn specimen (Fig. 2b) was constructed from a vertical column (hereinafter stud) and a horizontal element (hereinafter - rack). The $350 \mathrm{~mm}$ long studs were made of the same profile as Sn specimens. The racks represented U-shaped cold-formed profile without any perforations on webs. The flanges of every stud were fixed with $4+4$ selfdrilling screws on the flanges of the racks. The studs were fixed to the head of the hydraulic cylinder. The racks were fixed rigidly to the test frame. The specimens were loaded using the displacement control until the failure. The loading rate was $1.5 \mathrm{~mm} / \mathrm{min}$.

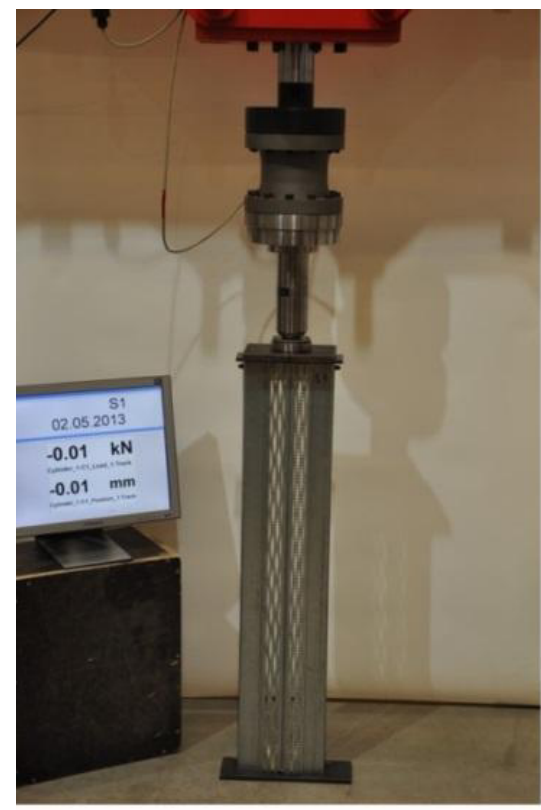

a)

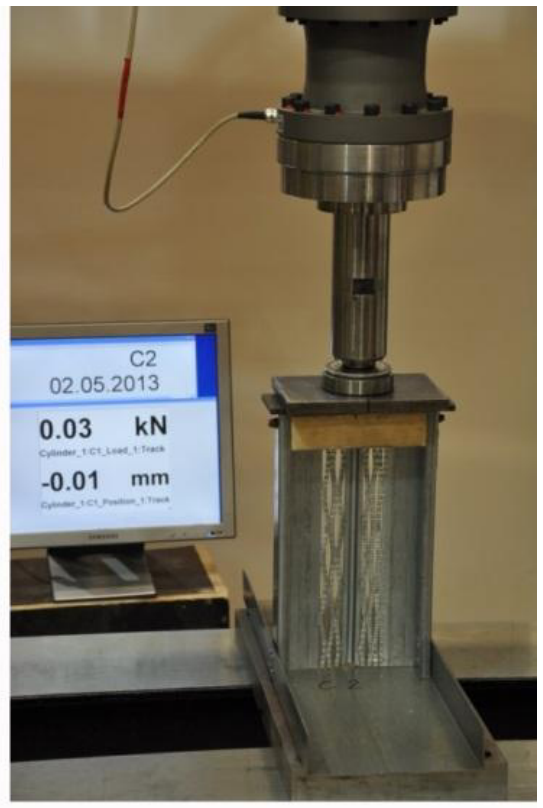

b)

Fig. 2. Overall view of test setup: (a) S1; (b) C2.

During the experiments every tested specimen experienced local buckling with subsequent global (flexural) buckling. A summary of the buckling test results is given in Table 2 .

Table 2. Characteristics of the samples tested.

\begin{tabular}{|c|c|c|c|c|c|c|c|c|}
\hline Specimen & $\mathrm{S} 1$ & $\mathrm{~S} 2$ & $\mathrm{~S} 3$ & mean & $\mathrm{C} 1$ & $\mathrm{C} 2$ & $\mathrm{C} 3$ & mean \\
\hline Length, $\mathrm{mm}$ & 1000 & 1000 & 1000 & 1000 & 350 & 350 & 350 & 350 \\
\hline Force, $\mathrm{kN}$ & 84.4 & 68.9 & 83.4 & 78.9 & 90.8 & 91 & 99.9 & 93.9 \\
\hline
\end{tabular}

The observed failure mechanisms of the Sn and Cn columns are shown in Figs. 3 and 5 respectively. Figs. 4 and 6 illustrate the load-displacement curves for the tested columns. 


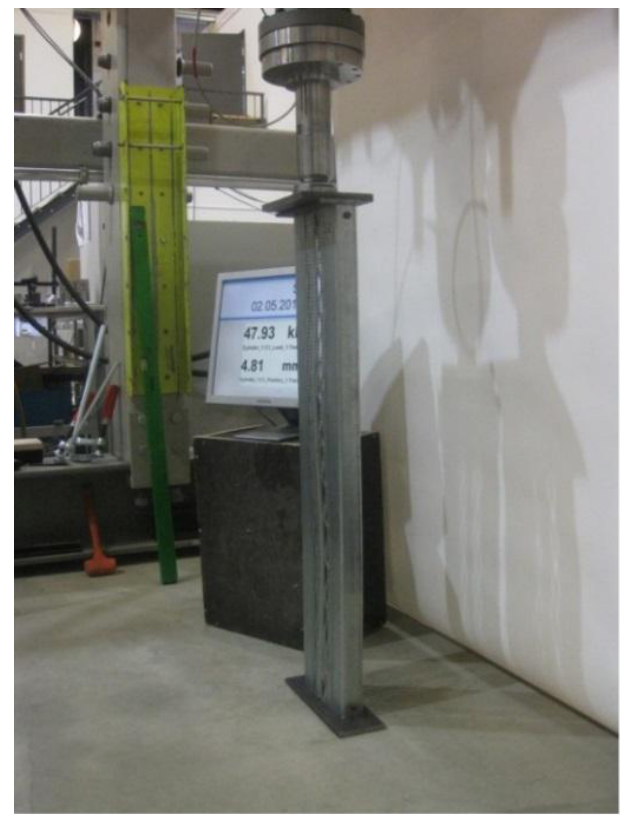

a)

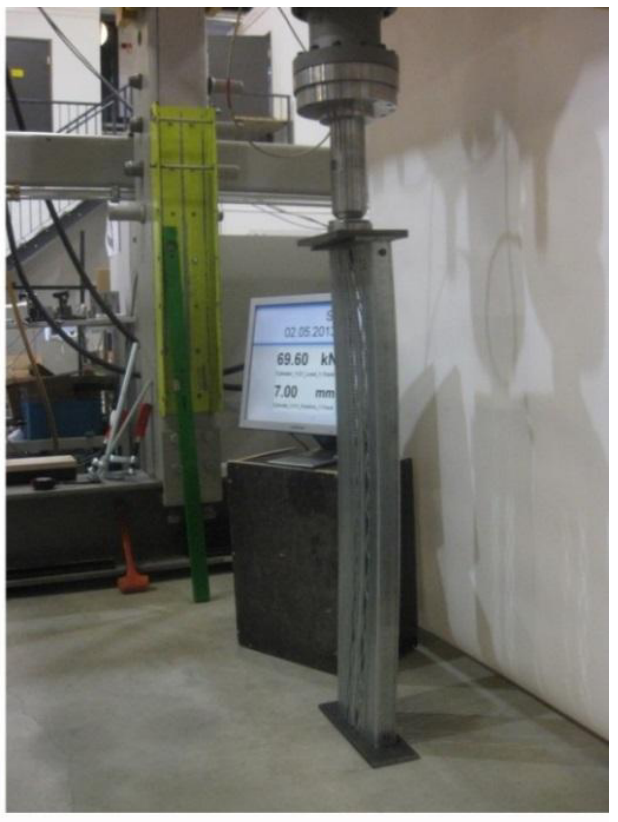

b)

Fig. 3. Observed failure mechanisms for tests on S2: (a) local buckling; (b) global (flexural) buckling.

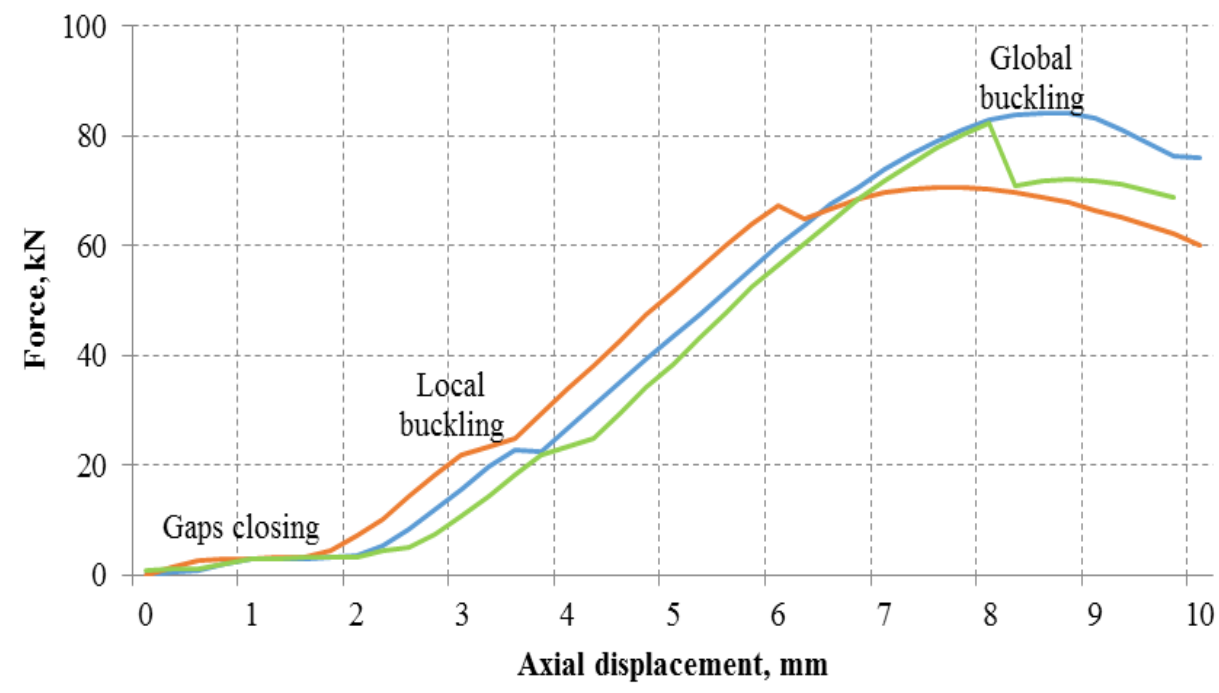

$-\mathrm{S} 1-\mathrm{S} 2-\mathrm{S} 3$

Fig. 4. Force-displacement response for Sn specimens. 


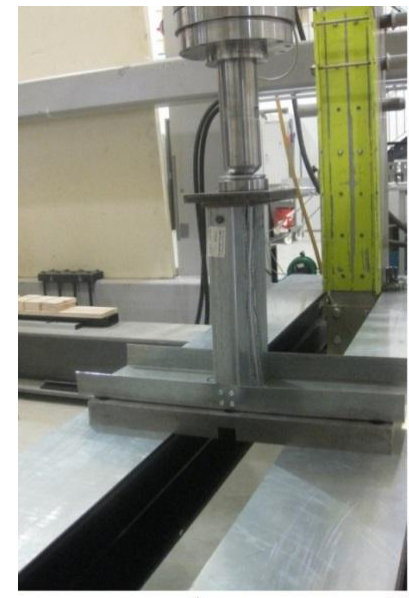

a)

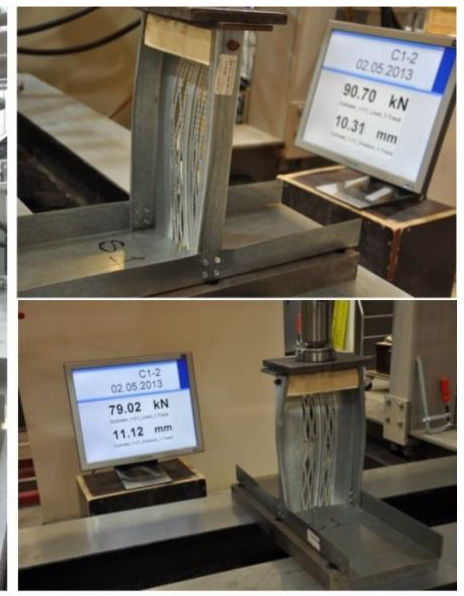

b)

Fig. 5. Observed failure mechanisms for tests on $\mathrm{C} 1$ : (a) local buckling; (b) global (flexural) buckling.

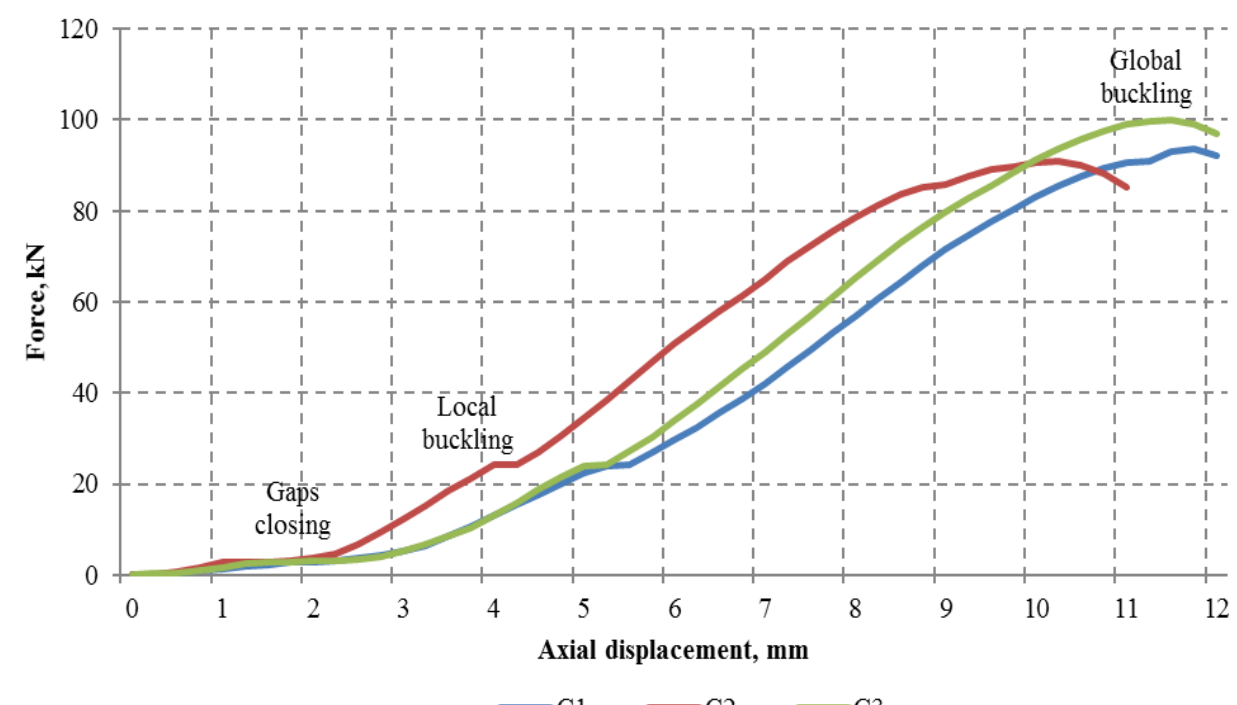

Fig. 6. Force-displacement response for $\mathrm{Cn}$ specimens.

Since the fact that the ends of all specimens were cut manually using a circular metal saw, on both load-displacement curves a short plateau shortly after the beginning of loading process was observed. On that step the gaps arisen as the result of cutting were closed making the force applied to the whole section of the profile. After the gaps were closed the curves behaved linearly with a very short plateau marking local buckling accompanied by a typical cotton. Then both curves continued growing gradually up to global buckling. One can see that for S1 specimen after the global buckling started the curve declined smoothly whereas for S2 and S3 specimens the noticeable drops were observed probably arisen as a results of initial geometric imperfections. At the same time, short specimens $(\mathrm{Cn})$ did not have such drops. 


\section{Finite element analysis}

To validate the experimental data FE buckling analysis in Abaqus was conducted. The simulation was arranged in such a way to repeat the tests: $1000 \mathrm{~mm}$ and $350 \mathrm{~mm}$ columns made of RST-profile were loaded by compressive loads. Geometrical properties of the RST-profile used for tests and modelling are presented in Fig. 7.
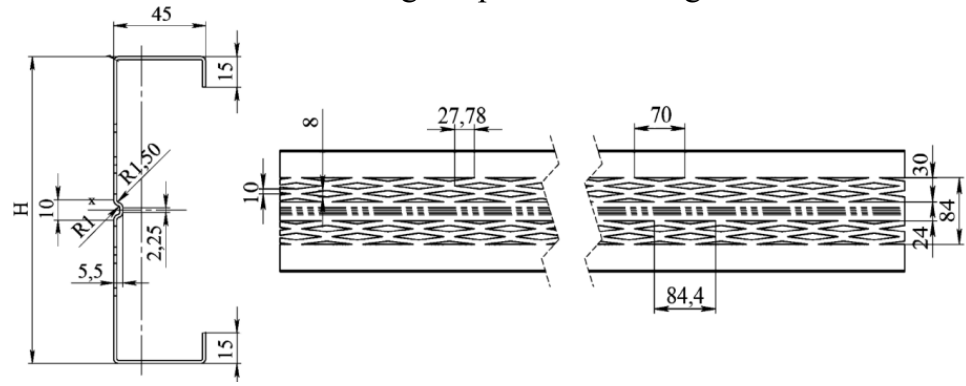

Fig. 7. Geometrical dimensions of RST-profile.

The mesh of the models was created using 4-node, quadrilateral, shell elements (S4R). The boundary conditions are shown in Fig. 8. All the models were loaded with concentrated compressive forces acting in $\mathrm{Z}$ direction. To simulate the wooden plates the rigid bodies at both ends of each specimen were created.

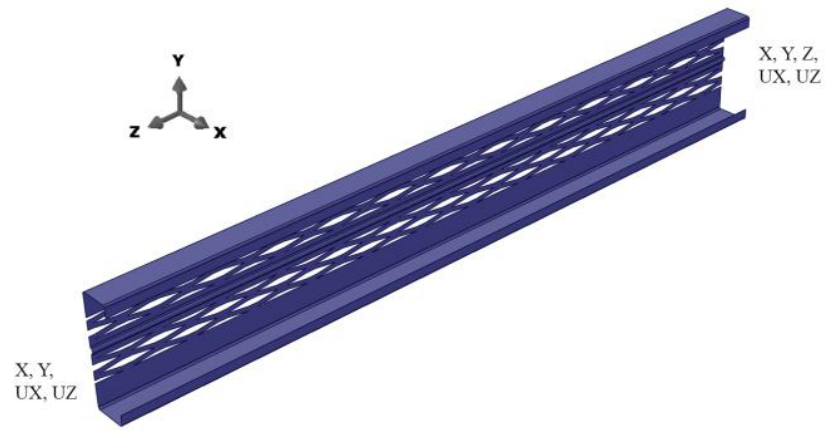

Fig. 8. Boundary conditions of the members tested.

For each column a buckling analysis with physical and geometrical nonlinearity ("Static, Riks") was performed. The results of the FE analysis are presented in Table 3. The table includes the buckling forces determined experimentally, by modelling and analytically by EN 1993-1-3-2009. Fig. 9 illustrates the deformed shapes and the load-displacement curves for the specimen tested.

Table 3. The results of FE analysis.

\begin{tabular}{|c|c|c|c|c|}
\hline \multirow{2}{*}{ Specimen } & \multirow{2}{*}{ Length [mm] } & \multicolumn{3}{|c|}{ Force [kN] } \\
\cline { 3 - 3 } & & Experiments & FEM & EN 1993-1-3-2009 \\
\hline S1 & 1000 & 84.4 & & \\
\hline S2 & 1000 & 68.9 & \multirow{3}{*}{84.8} & \multirow{2}{*}{49.7} \\
\hline S3 & 1000 & 83.4 & & \\
\hline mean & & 78.9 & & \\
\hline C1 & 350 & 90.8 & \multirow{3}{*}{92.1} & \multirow{2}{*}{55.9} \\
\hline C2 & 350 & 91.0 & \\
\hline C3 & 350 & 99.9 & \multirow{2}{*}{} \\
\hline mean & & 93.9 & & \\
\hline
\end{tabular}




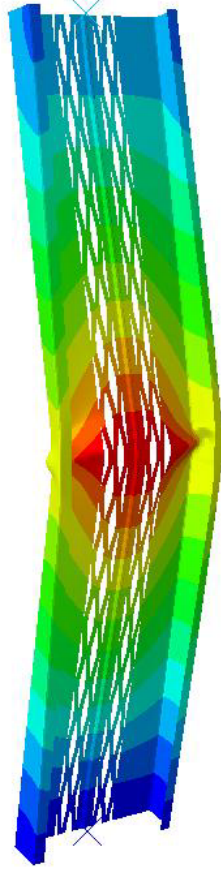

$\mathrm{Sn}$

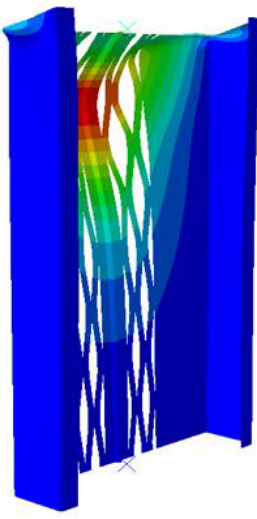

$\mathrm{Cn}$
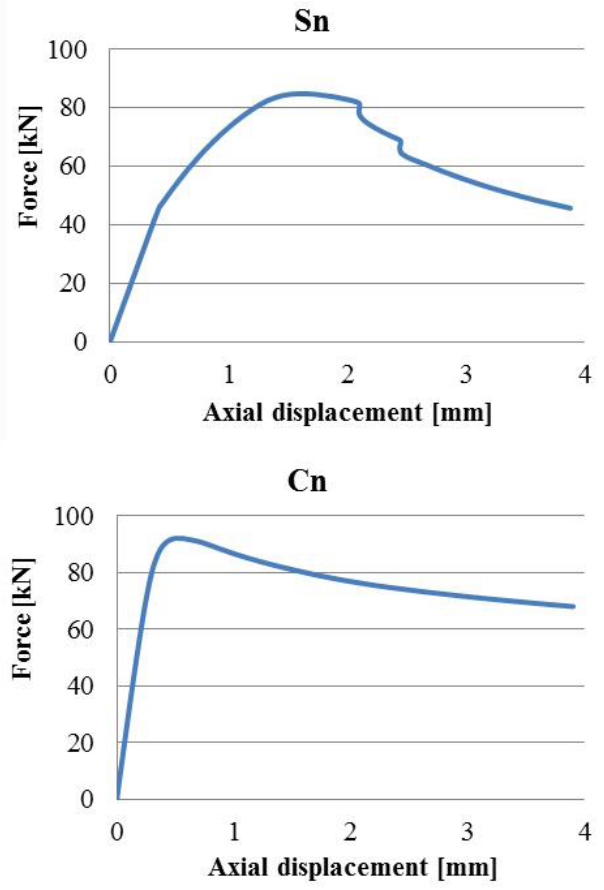

load-displacement curves

Fig. 9. Deformed shapes and load-displacement curves of simulation tests.

It can be seen that in case of modelling the load-displacement curves had the similar behavior as for experimental data but without closing gaps plateaus. Local buckling segment for $\mathrm{Sn}$ was reduced down to a certain point making the curve bilinear while for $\mathrm{Cn}$ it was not observed at all. For both cases global buckling was determined at points close to those for experimental tests.

FE analysis was also conducted for a solid-web profile (without any perforations on web) and a traditional thermoprofile to compare their bearing capacity to RST-profile. The results are presented in Table 4. For convenience, buckling forces of all profiles are divided to a buckling force of a solid-web profile $\left(\mathrm{F}_{\mathrm{SW}}\right)$.

Table 4. Comparison of RST-profile with solid-web CFS profile and traditional thermoprofile.

\begin{tabular}{|c|c|c|c|c|}
\hline \multirow{2}{*}{ Specimen } & \multirow{2}{*}{ Length [mm] } & \multicolumn{3}{|c|}{ F / $\mathrm{F}_{\mathrm{SW}}$} \\
\cline { 3 - 5 } & & Profile with solid web & Conventional thermoprofile & RST-profile \\
\hline $\mathrm{Sn}$ & 1000 & 1 & 0.69 & 0.96 \\
\hline $\mathrm{Cn}$ & 350 & 1 & 0.92 & 0.97 \\
\hline
\end{tabular}

It can be seen that due to the presence on intermediate longitudinal stiffener RST-profile has bearing capacity considerably higher than conventional thermoprofile with longitudinal perforations (particularly for long elements) and almost as high as solid-web CFS profile. 


\section{Conclusions}

Nonlinear FE models were developed and verified against previously conducted compression tests on cold-formed steel C-section columns of RST-profile. Due to rational geometry RST-profile has very high bearing capacity under compression, having relatively similar mechanical properties as CFS profile without thermal openings.

Computer simulations showed good agreement with the experimental data. Discrepancy between the results was less than $10 \%$. Despite the close results, the values of buckling forces for the tests and simulations corresponded to the different values of displacements. This might be the result of closing the gaps, which, in their turn, occurred due to the initial geometric imperfections of the columns.

Simulation tests for short columns $(350 \mathrm{~mm})$ showed very close results, however, the deformed shape obtained from modelling was completely opposite to the one from the experimental tests. This demonstrates the need for a more detailed modelling with the particular attention paid to nodal connections and wooden plates in the top of the models.

Analytical calculations made in accordance with EN 1993-1-3-2009 showed considerably lower results. This probably means that the building codes provide more reliable values of buckling forces for this type of profile.

Anyway, RST-profile remains poorly explored and requires more careful and detailed research. It also seems reasonable to provide computer modelling taking into account initial geometrical imperfections of the elements, since the fact that CFS structures with such perforations are very sensitive to any mechanical deformations.

The experimental work was conducted with the help of Dr. Arto Ranta-Eskola, director of research, Rautaruukki Oyj (Finland). The authors also gratefully acknowledge the helpful comments of Prof. Milan Veljkovic (Luleå University of Technology).

\section{References}

1. M. Veljkovic, B. Johansson, J. Constr. Steel Res., 64, 7-8 (2008) 816-821

2. M. Heinisuo, J. Lahdenmaa, T. Jokinen, Proceedings of the 12th International Conference on Steel, Space and Composite Structures, (2014) 85-97

3. M. Pavlović, C. Heistermann, M. Veljković, D. Pak, M. Feldmann, C. Rebelo, L.S. da Silva, J. Constr. Steel Res., 115, (2015) 458-466.

4. M. Pavlović, C. Heistermann, M. Veljković, D. Pak, M. Feldmann, C. Rebelo, L.S. da Silva, J. Constr. Steel Res., 115, (2015) 445-457

5. V.K. Vostrov, A.A. Vasilkin, Montaz. i Spetsial'nye Rab. v Stroit., 11, (2005) 37-39

6. G. Kashevarova, P. Kosykh, Appl. Mech. Mater., 670-671, (2014) 466-473

7. S. Kesawan, M. Mahendran, Thin-Walled Struct., 98, (2016) 111-126

8. S. Kesawan, M. Mahendran, J. Constr. Steel Res., 115, (2015) 191-205

9. V. Ungureanu, M. KoteŁko, R.J. Mania, D. Dubina, Thin-Walled Struct., 48, 10-11 (2010) 818-826

10. C.D. Moen, B.W. Schafer, Eng. Struct., 31(12), (2009) 2812-2824

11. M. Garifullin, N. Vatin, Constr. Unique Build. Struct., 6, (2014) 32-57

12. V. Lalin, V. Rybakov, A. Sergey, Appl. Mech. Mater., 578-579, (2014) 858-863

13. V. Rybakov, A. Sergey, Appl. Mech. Mater., 725-726, (2015) 746-751

14. G. Belyj, E. Serov, World Appl. Sci. J., 23(13), (2013) 160-164

15. M. Al Ali, Adv. Mater. Res., 969, (2014) 93-96

16. M. Al Ali, M. Tomko, I. Demjan, V. Kvočák, Procedia Eng., 40, (2012) 8-13

17. M. Al Ali, M. Tomko, I. Demjan, V. Kvocak, Komunikacie, 14(4), (2012) 83-87

18. A.R. Tusnin, Montaz. i Spetsial'nye Rab. v Stroit., 2, (2003) 4-7 
19. A.R. Tusnin, Montaz. i Spetsial'nye Rab. v Stroit., 4, (2003) 12-14

20. A.R. Tusnin, Montaz. i Spetsial'nye Rab. v Stroit., 9, (2003) 2-4

21. A.R. Tusnin, Promyshlennoe i Grazhdanskoe Stroit., 6, (2003) 59-6.

22. A.R. Tusnin, Montaz. i Spetsial'nye Rab. v Stroit., 3, (2003) 2-4

23. O. Tusnina, Appl. Mech. Mater., 467, (2014) 398-403

24. O. Tusnina, Appl. Mech. Mater., 475-476, (2014) 1483-1486

25. A. Danilov, O. Tusnina, J. Appl. Eng. Sci., 12(2), (2014) 153-158

26. M. Garifullin, U. Nackenhorst, Procedia Eng., 117, (2015) 1078-1084

27. A.R. Tusnin, M. Prokic, J. Appl. Eng. Sci., 12(3), (2014) 179-186

28. A.R. Tusnin, M. Prokic, Procedia Eng., 111, (2015) 789-796

29. A.R. Tusnin, M. Prokic, Mag. Civ. Eng., 5(49), (2014) 44-53

30. T. Björk, H. Saastamoinen, Tubular Structures XIV - Proceedings of the 14th International Symposium on Tubular Structures, ISTS 2012 (2012) 167-176

31. S. Heinilä, T. Björk, G. Marquis, ASTM Spec. Tech. Publ. 1508 STP (2009) 200-215

32. T. Nykänen, T. Björk, H. Mettänen, A. V. Ilyin, M. Koskimäki, Fatigue Fract. Eng. Mater. Struct., 37(3), (2014) 325-334

33. D. Ungermann, S. Lübke, B. Brune, Thin-Walled Struct., 81, (2014) 108-120

34. D. Ungermann, B. Brune, S. Lübke, Steel Constr., 5(4), (2012) 205-211

35. Y. Shifferaw, B.W. Schafer, Thin-Walled Struct., 80, (2014) 142-152

36. N. Vatin, J. Havula, L. Martikainen, A. Sinelnikov, A. Orlova, S. Salamakhin, Tests and FEM-Modelling, Adv. Mater. Res., 945-949, (2014) 1211-1215

37. N. Vatin, J. Havula, L. Martikainen, A. Sinelnikov, L.L. Shurovkina, Appl. Mech. Mater., 725-726, (2015) 722-727

38. N. Vatin, J. Havula, L. Martikainen, A. Sinelnikov, A. Orlova, S. Salamakhin, Proceedings of the International Conference „Innovative Materials, Structures and Technologies" (2014) 187-192

39. N. Vatin, T. Nazmeeva, R. Guslinscky, Adv. Mater. Res., 941-944, (2014) 1871-1875

40. T.V. Nazmeeva, Mag. Civ. Eng., 5, (2013) 44-51

41. D. Trubina, D. Abdulaev, E. Pichugin, M. Garifullin, Appl. Mech. Mater., 633-634, (2014) 1052-1057

42. N. Vatin, A. Sinelnikov, M. Garifullin, D. Trubina, Appl. Mech. Mater., 633-634, (2014) 1037-1041

43. D. Trubina, D. Abdulaev, E. Pichugin, V. Rybakov, M. Garifullin, O. Sokolova, Appl. Mech. Mater., 725-726, (2015) 752-757

44. M. Garifullin, D. Trubina, N. Vatin, Appl. Mech. Mater., 725-726, (2015) 697-70 